\title{
CONSUMER ATTITUDES TOWARDS MULTI-CHANNEL RETAILERS' \\ WEB SITES: THE ROLE OF INVOLVEMENT, BRAND ATTITUde, INTERNET KNOWLEDGE AND VISIT DURATION.
}

\author{
George Balabanis \\ City University Business School \\ London, England \\ Nina L. Reynolds \\ University of Wales Swansea \\ Swansea, Wales
}

\begin{abstract}
The study examines how different consumers evaluate online shopping sites set up by bricks-and-mortar retailers. In particular, it examines how differences in consumers'information processing abilities and motivation as well as in theirpredispositions towards a site's material affect their attitudes towards that site and the amount of time they spend at the site. The postulated relationships are depicted in the form of a path diagram. The sites assessed were two electronic shopping sites belonging to well established casual wear multi-channel retailers. Findings suggested that attitudes towards a retailer's brand (predisposition) transfers to attitudes towards the retailer's shopping site. The characteristics of the web site were found to moderate the impact of involvement, Internet knowledge and Internet experience, on both attitudes towards a site and the visit duration.
\end{abstract}

\section{Introduction}

The revenue generated from Internet shopping is increasingly rapidly in terms of both its share of all retail sales and its overall value (Economist 2/26/00;6/2/ 00 ). Sales from multi-channel retailers (catalogue and/or physical stores that also sell on-line) dominate this outlet, and they are expected to increase their dominance as the Internet matures (Economist 8/21/99). Businesses recognized, however, that use of the Internet should not be restricted to sales - functions such as "building brand awareness" and "providing marketing information" are also relevant (www.yankeegroup.com). These trends and issues, alongside the changing nature of consumers' online shopping habits, reduce the importance of traditional distribution channels to retailers (e.g., Quelch \& Klein, 1996; Hoffman, Novak \& Catterjee, 1995; Hamill \& Gregory, 1997).

The role of the Internet, in particular, of electronic commerce web sites, has been recognized as a marketing tool for attracting and maintaining customers (Dreze \& Zufryden, 1997; Vrolijk, Huizingh \& Hoekstra, 1998; McMurdo, 1998; Dholakia \& Rego, 1998; Hofacher \& Murphy, 1998; O'Keefe, O'Connor 
\& Kung, 1998). Settles (1995) has claimed that one of the most important elements of a web site's value to customers is the provision of pre-purchase sales information. Web site technology can allow consumers to view different product features, assess possible product attribute combinations and/or compare competitive offerings. However, the attractiveness and appeal of a web site is not the same to all customers (Settles, 1995). Nevertheless, despite the emphasis placed on the marketing potential of the Internet and the need for well-designed web sites, very little is known of consumer differences regarding their attitudes towards a web site. Specifically, there is very little academic research on the impact of consumer behavior on online shopping at web sites set up by bricksand-mortar retailers (Katros, 2000).

Based on the above, the main objective of this study is to examine consumers' attitudes towards a multi-channel retailer's web site. Drawing from research in psychology (Petty \& Cacioppo, 1986; Chaiken, Liberman \& Eagly, 1989) and advertising (MacInnis \& Jaworski, 1989), the study concentrates mainly on the differences between individuals in terms of motivation, ability to process information and attitudes towards the brand.

\section{Literature Review and Model Development}

While consumer Internet research has considered the virtues of the medium and its potential uses (Berthon, Pitt \& Watson, 1996), innovation diffusion and consumer Internet adoption (Gupta \& Rabikar, 1997; Keeling \& McGoldrick, 1997; Keeling, Fowler \& McGoldrick, 1998; White, Abels \& Murnane, 1998), and how, with certain product categories, consumer buying can be modeled (Liang \& Huang, 1998), it is still limited in scope. A popular Internet research topic is web site effectiveness, where researchers have focussed on web site design features and content (Dreze \& Zufryden, 1997; Vrolijk et al., 1998), profiles of effective web sites (Johnson, Cleland, Williamson, Carmichael, Gleason, Cuneo, Mandese, Waltner, Donaton, Zbar, Haran \& Fawcett, 1995), and the features that make a 'good' web site (McMurdo, 1998; Dholakia \& Rego, 1998; Hofacher \& Murphy, 1998). Nevertheless, little attention has been given to how consumers' differences affect their use and evaluation of web sites.

How consumers' use web sites is highly dependent on how they processes information, as such this study draws from the information processing evaluation literature (e.g., Petty \& Cacioppo, 1986; Chaiken et al., 1989). In addition, work on advertising evaluation, in particular the role of attention and preexisting brand attitudes on information processing/evaluation, is also drawn upon (MacInnis \& Jaworski, 1989). According to these authors, the processing and evaluation of information depends primarily on three factors; the individual's (i) motivation, (ii) ability, and (iii) opportunity to process information. The importance of these factors to the Internet, particularly Internet navigation behavior, has been recognized by Hoffman et al. (1996). 
How relevant the information presented is to the consumer, that is the consumer's level of involvement, impacts on their motivation to process that information (MacInnis \& Jaworski, 1989). Involvement can also have an impact on the way information is processed (see Johnson \& Eagly, 1989; 1990). It can influence both the direction and intensity of an individual's attention. Attention itself refers to the allotment of an individual's mental activity to the task of concern (MacInnis \& Jaworski, 1989). Increased duration on a web site is a manifestation of increased attention, which, in turn, is an indication of increased motivation (i.e., higher level of involvement).

The second factor, ability to process information, refers to the consumer's skill or proficiency in interpreting information. Factors such as intelligence or education, product knowledge or experience, and message difficulty, influence an individual's information processing ability (MacInnis \& Jaworski, 1989). Web sites, which provide information through a complex nexus of hypertext links, may restrict the information processing ability of those consumer's that are inexperienced with and/or not knowledgeable about the Internet ${ }^{\prime}$. As such, consumer's that are experienced of and knowledgeable about the Internet, will have greater ability to process and evaluate the information found on a web site.

The third factor considered in this study, situational and information-related effects, can obstruct the interpretation process and the time spent processing information and, as such, have an impact on the consumers' opportunity to process information (Macinnis \& Jaworski, 1989). The opportunity to process information can be influenced by features that distract consumers' attention from the message evaluation (e.g., background music, source, etc.) or factors such as the level of information condensation and the pace of the delivery of the message. Ceteris paribus, individuals with different levels of opportunity to process a piece of information will form different views about that information. Ideally, individuals would process any information presented to them free of bias or preconceptions. However, individuals often have a pre-formed set of attitudes about the brands marketed on web sites or about the owners of the sites. Consumers' attitudes towards a brand (or $A_{b}$ ), for example, are likely to affect the way they process the information presented on that brand's web site and the formation of attitudes towards that web site $\left(A_{w c h}\right)$. Corresponding research in advertising, for example, has found that attitudes towards an advertisement $\left(A_{a d}\right)$ are highly correlated to $A_{b}$ (MacKenzie, Lutz \& Belch, 1986). This may be because consumers do not devote enough attention to the advertisement to distinguish it from the brand, or it may be that exposure to the advertisement helps consumers to retrieve brand associations (MacInnis \& Jaworski, 1989). Although there are certain differences between the way information is presented in an advertisement and on a web site, the rationale advocating a relationship between brand attitudes and attitudes towards the associated web site remain pertinent. 
Consequently, this study focuses on the impact of these areas when considering consumers' attitudes towards web sites: (i) consumer involvement with the product category (motivation factors); (ii) Internet/knowledge experience (ability factors); (iii) pre-existing attitudes towards a brand (opportunity factors). Their relationships with (a) attitudes towards an electronic shopping web site $\left(\mathrm{A}_{\mathrm{web}}\right)(\mathrm{b})$ duration of a visit to that site, as well as (c) their inter-relationships, are depicted in Figure 1.

\section{Figure 1}

The Relationship Between Involvement, Brand Attitude, Internet Knowledge and Experience, Visit Duration and Attitudes Towards a Web Site

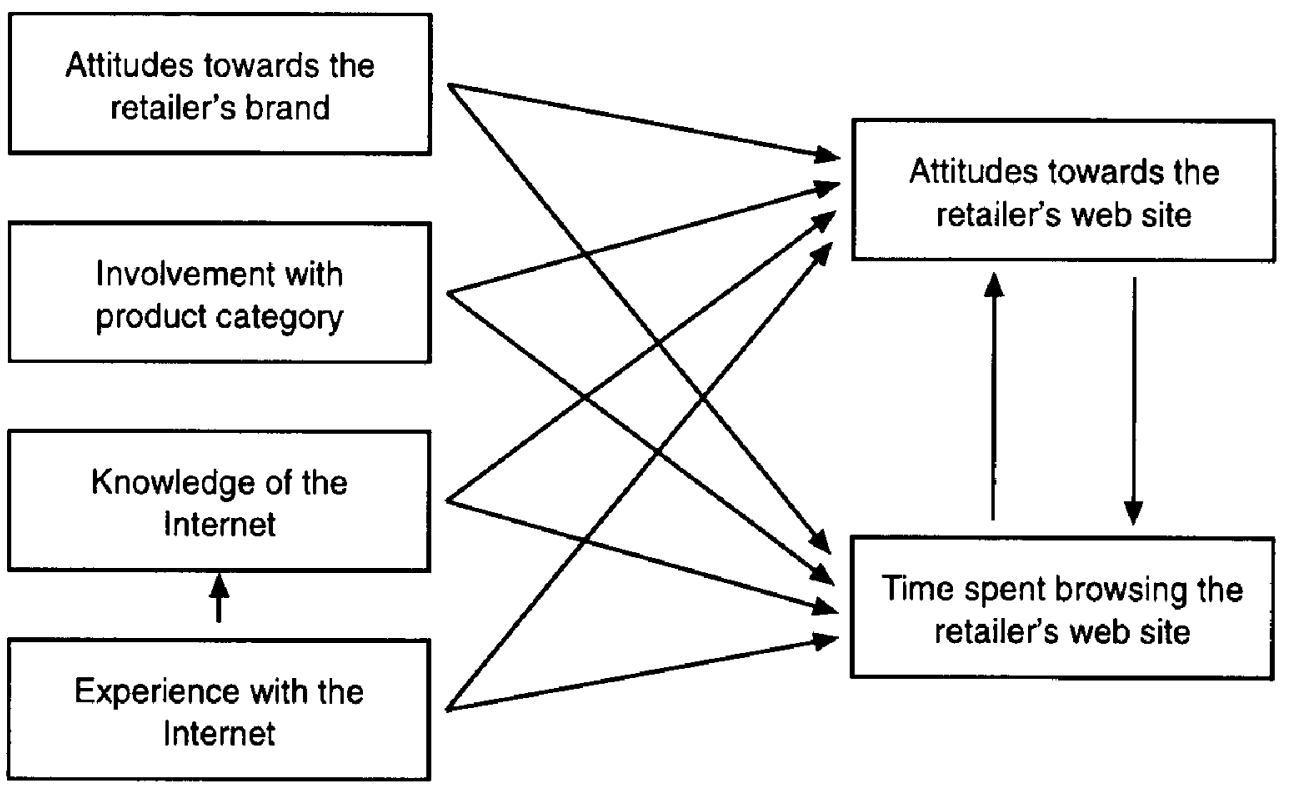

\section{Involvement With a Product Category}

Consumers will process information presented to them in detail and make complex evaluations only if they are motivated (Petty \& Cacioppo, 1986); an individual's motivation to process information about an issue is his/her level of involvement with that issue (see Johnson \& Eagly, 1989; 1990 for review). In the case of commercial web sites, the "issue" is usually a set of products or services.

The level of involvement a consumer has with a product is based on the relevance of that product to the consumer's inherent needs, values and interests (Zaichkowsky, 1985). In turn, involvement influences the amount of mental and physical effort a consumer puts into the buying process (Laaksonen, 1994). Highly-involved consumers will: (i) search for more information before they 
buy; (ii) process relevant information in greater detail; and (iii) use more criteria in their buying decisions than other consumers (Maheswaren \& Meyers-Levy, 1990; Leong, 1993; Laaksonen, 1994). Involvement also affects consumers' levels of attention, information processing, comprehension, decision-making and responses to advertising (Celsi \& Olson, 1988; Maheswaren \& MeyersLevy, 1990). For example, highly involved consumers will pay greater attention to relevant web sites than less involved ones (Hoffman \& Novak, 1996).

Highly involved individuals also appear to process relevant information more conscientiously than less involved ones. Petty and Cacioppo (1986), for instance, have shown that cogent information is more effective for highlyinvolved individuals than for less involved ones, while specious information is less effective for highly involved individuals than for less involved ones. Thus, involved consumers are likely to react differently to a web site and provide different evaluations of that site than less involved consumers. Aspects of the web site related to the object of involvement (i.e., the product) are more likely to attract the interest of involved consumers, whereas, uninvolved consumers are likely to focus more on the peripheral stimuli of the site (visuals, sounds, frames, etc.) or the site's design characteristics. Thus, the relationship between involvement and attitudes toward the web site is partially dependent on the characteristics of the site. In addition, highly involved individuals are expected to spend more time at a web site gaining information about a product. Thus,

Hypothesis 1A: The length of time a consumer spends on a web site is positively related to his/her level of involvement with the product category featured on that web site.

Hypothesis 1B: A consumer's attitude towards a web site is positively related to his/her level of involvement with the product category featured on that web site.

\section{Experience with and Knowledge of the Internet ${ }^{2}$}

Consumers' attention and reaction to received information depends on their information processing ability. The ability to comprehend and interpret information is influenced by education, intelligence, product experience, relevant knowledge, and message difficulty (MacInnis \& Jaworski, 1989; Petty \& Cacioppo, 1986). Knowledgeable consumers can, however, lack the excitement of a novice when processing a piece of information (motivational factors). Nevertheless, experience and knowledge provide the background to recognize strong or weak points in a piece of information. Moreover, knowledge can influence a consumer's information processing by prompting or enabling individuals to argue for or against a piece of information (rather than passively accept it). 
In relation to the Internet, experienced and knowledgeable users may lack motivation and adopt a "we've seen it before attitude" to web site features. These users have a large comparison base of web sites and are able to spot technical flaws more easily than less knowledgeable/experienced users. Such experienced users are attracted to, and spend more time at, technically advanced sites, or sites with novel features that present more challenges to them (Hoffman \& Novak, 1996). They are also more likely to appreciate technical web site design features that are not easily discernible to less knowledgeable/experienced Internet users. The above factors will have an impact on the way these users process the information presented in a site and the attitudes they form towards a site. Consequently, while experienced users are prone to get bored with under-challenging web sites, novice users are likely to experience anxiety from over-challenging (Hoffman \& Novak, 1996). Thus, both experience and knowledge will be related to the individual's attitudes towards the site. However, the direction of that relationship will vary according to the characteristics of the site. Additionally, knowledgeable and experienced Internet users are more efficient at navigation and web site browsing than those without experience or knowledge. Consequently, consumers with Internet experience and/or knowledge will spend less time browsing web sites than users without; less experienced/ knowledgeable users need more time to read and understand Web site instructions and to identify navigational shortcuts (e.g., buttons). From the above discussion the following hypotheses emerge:

Hypothesis $2 \mathrm{~A}:$ Internet experience is negatively related to the length of time an individual spends at a web site.

Hypothesis 2B: Internet experience is related to an individual's attitudes towards a web site.

Hypothesis 2C: Internet knowledge is negatively related to the length of time an individual spends at a web site.

Hypothesis 2D: Internet knowledge is related to an individual's attitude towards a web site.

Internet knowledge, that is the level of understanding of the medium, can be gained via online experience or from other sources (e.g., technical manuals). Continuous use of the Internet is, however, likely to result in Internet knowledge if the user intentional, or unintentional, experiments and observes the results of those experiments. As such, one would expect that use of the Internet would increase an individual's knowledge of the Internet. That is:

Hypothesis 2E: Internet experience is positively related to Internet knowledge. 


\section{Prior Attitudes Towards a Brand}

Consumers' attitudes towards a web site (or advertisement) are likely to be conditioned by any prior attitudes towards the brand associated with that web site. Although there is some debate over which of these attitudes (web site/advertisement or brand) the consumer forms first (Brown \& Stayman, 1992; MacKenzie et al., 1986), there is no debate of the presence of a relationship. According to the brand attitude and advertising literature (Brown \& Stayman, 1992; MacKenzie et al., 1986), a positive attitude towards an organization's brand predisposes a positive attitude towards the organization's advertisements and other communications. By the same token, it can be assumed that consumers will spend more time on web sites owned by favored organizations than on those of unfavored organizations. Based on the above the following hypotheses are formulated:

Hypothesis 3A: An individual's brand attitude is positively related to his/her attitude towards that brand's web site.

Hypothesis 3B: An individual's brand attitude is positively related to the length of time that he/she will spend at that brand's web site.

\section{Attitudes Towards a Web Site and Visit Duration ${ }^{3}$}

The last area to be considered concerns the relationship between attitude toward the web site and visit duration. Similar to advertisements, the characteristics of the Internet are likely to influence both the amount and pace of a visitor's exposure to information (Thorson, Chi \& Leavitt, 1992). Literature suggests that both amount of information and speed of processing would be related to an individual's attitude towards a web site (cf. Olney, Holbrook \& Batra, 1991). Given the same speed of processing, an individual that devotes more time to a web site will process more information and notice more details than an individual that only visits the site briefly. It is also likely that longer visits will allow the visitor the time to reflect on the information more carefully. Thus, visiting time increases the possibility of an individual's attention to, processing of, and reflection on a larger amount of information that, in turn, is likely to lead to better comprehension of the information (cf. Olney, Holbrook \& Batra, 1991). However, it appears that there is a bi-directional (non-recursive) relationship between visit duration and attitudes towards a web site (cf. Thorson, Chi \& Leavitt, 1992). On the one hand, individuals will spend more time at a web site that is to their liking; if they do not like the web site then they will move onto another more pleasing site. Conversely, if an individual is searching for something specific on a web site and cannot find it, then s/he will have to spend more time on that web site. However, s/he is likely to become increasingly frustrated with it than if the information was easily found. Consequently, it is important to determine whether increasing visit duration corresponds with increasingly posi- 
tive attitudes towards the web site; if it does not, then improvements to the web site may be required. If the relationship between favorable attitudes towards the site and visit duration is positive, then falling duration would indicate that improvements were needed on that web site.

Thus, the following two hypotheses can be put forward:

Hypothesis 4A: An individual's attitudes towards a web site are positively related to the length of time he/she spends at that site.

Hypothesis 4B: The length of time an individual spends at a web site is related to his/her attitudes towards the site.

\section{Research Methodology}

As part of the research process involved the browsing and evaluation of two web sites this study required subjects that could, and were able to, access the Internet. Sample selection was restricted as (i) the evaluation process was relatively time-consuming, and (ii) control over the order in which some of the measures were presented was required (e.g., prior attitudes towards the brand needed to be measured before the formation of attitudes towards the brand's web site). In addition, to help ensure a narrow range of information processing ability, subjects with similar levels of education were needed. These restrictions led to the use of an undergraduate student sample.

Students working in a University's computer labs were approached and asked if they knew how to use an Internet browser and whether they would like to participate in the study. Care was taken with the sample selection to ensure a gender balance, and participants were screened to check that they had not visited the selected web sites previously. Respondents qualified to take part in the study filled-in the initial sections of a questionnaire and then browsed two bookmarked electronic shopping web sites. No time restriction was placed on their visit duration. When they finished browsing, respondents' attitudes towards each web site $\left(A_{\text {web }}\right)$ were measured. The web sites used for the study belonged to two store-based retailers, "Gap" and "Principles", with relatively high brand recognition. These retailers were selected because both:

(i) sell casual clothes, a product category relevant to the sample selected. (Moreover, clothes are a popular product category for traditional home-shoppers, that is, print catalogue shopping, with $41 \%$ of all home-shopping coming from clothing FT 3/13/98.);

(ii) were new to electronic-shopping with recently established web sites (i.e., www.gap.com/onlinestore/storefront.asp and www.principles.co.uk/promoinvocation; and, 
(iii) sell products that carry only their own brand names (i.e., "Gap" and "Principles" respectively). This prevents the emergence of effects originating from attitudes towards other brands stocked by the retailers.

In total 102 students participated in the study (56\% males; $44 \%$ females) with ages ranging from 18 to 32 years. The research instrument, a questionnaire, was pre-tested on five subjects using the debriefing approach (Hunt, Sparkman \& Wilcox, 1982).

\section{Measures}

Involvement. Zaichowsky's (1985) personal involvement inventory, a sevenpoint bipolar semantic differential scale, with items such as important/unimportant, irrelevant/relevant, boring/interesting, was used to measure involvement in buying casual clothes. LISREL 8 (Jöreskog \& Sörbom, 1993) showed an unacceptable initial fit for the one factor model. A model modification procedure was undertaken (Gerbing \& Anderson, 1988; Kaplan, 1990). The final scale consisted of eleven items (Appendix 1) and had acceptable levels of fit on all indices (Jöreskog \& Sörbom, 1993) and coefficient alpha of 0.938 , well above Nunnally and Bernstein (1994) recommended level of 0.70 . The scale construct validity statistic was equal to 0.938 (acceptable minimum .70) and the extracted variance equal to 0.641 (acceptable minimum .50). Both statistics were well above the recommended cut-off points (Hair, Anderson, Tatham \& Black, 1995).

Prior attitudes towards a brand. Aaker's (1996) inventory measured attitudes towards the two brands considered. Following his advice, only the seven items that closely matched the objective of the study were used - good value for money, trustworthy, innovative, admirable, high quality, consistent quality and interesting. Respondents indicated how well each described both the "Gap" and "Principles" brands using a seven-point scale (not at all to very much so). Confirmatory factor analysis using Kaplan's (1990) modification procedure resulted in the removal of two items (i.e., trustworthy and consistent quality of the brand). The remaining items had acceptable levels of fit for both "Gap" and "Principles" (see Appendix 2). The values of the respective construct validities (0.846 and 0.871$)$ and extracted variances $(0.530$ and 0.594$)$ were above their acceptance thresholds. Cronbach's alpha on the remaining items was .863 and .853 respectively.

Attitudes towards a web site. Items were drawn from measures of attitudes towards advertisements (Hill \& Mazis, 1986; Gardner, Mitchell \& Russo, 1985). For each web site a seven-point bipolar scale with nine items was used - very $\mathrm{bad} /$ very good, uninteresting/ interesting, dislikable/likeable, unfavorable/favorable, poor quality/good quality, disagreeable/ agreeable, confusing/clear, uninformative/informative, low/high attention grabbing ability. The scales were applied after the web sites had been browsed, nevertheless, confirmatory factor 
analysis using LISREL 8 required the removal of three items (very bad/very good, dislikable/likeable, uninformative/informative) to achieve an acceptable level of fit for both the "Gap" and "Principles" scales (see Appendix 3). With the remaining six items Cronbach's alpha for the "Gap" scale was $.838, .851$ for the "Principles" scale. The reported construct validities $(0.858$ and 0.853$)$ and extracted variances $(0.517$ and 0.506$)$ of both scales were at acceptable levels. Experience with and Knowledge of the Internet. Experience refers to the length of time an individual has used the Internet for, as such, respondents were asked to indicate approximately how long they had used the Internet for and, on average, how many hours a week they spent on it. The product of these two indices (converted into weeks) was used as a measure of Internet experience. In this sample respondents had, on average, been using the Internet for 19.516 months (standard deviation 13.448) with an average frequency of 7.196 hours a week (standard deviation: 6.549). Following Park, Mothersbaugh and Feick's (1994) suggestion to use objective rather than perceived knowledge measurement, respondents' knowledge of the Internet was assessed using five questions on a multiple-choice test (see Appendix 4). The average score in that test was 2.951 with a standard deviation 1.423 .

\section{Results}

Before testing the specific hypothesis, overall ratings are required for the a priori attitudes of respondents to the two brands. Overall, the "Gap" brand is stronger than the "Principles" brand with this sample (arithmetic means 23.614 and 19.783 , standard deviations 5.254 and 4.889 respectively) $)^{4}$. This difference is significant at $\alpha=0.001$. In line with brand attitudes, the evaluations of the two web sites also showed significant differences when $\alpha=0.001$ (Gap mean $=$ 28.928 , standard deviation $=6.346$, Principles mean $=25.990$, standard deviation $=6.602)^{5}$. While these results are not surprising given the age of respondents and the nature of the web sites, the purpose of this study is not to compare the two web sites per se, but to use the differences in respondent's ratings to empirically test the hypothesis in two contexts (i.e. the two web sites). However, while differences existed in the evaluations of the web sites, there was no significant difference in the length of time spent browsing each site $(t-v a l u e=$ $.456, p=.650$; "Gap" mean $=15.218$ minutes, standard deviation $=20.252$; Principles mean $=15.807$, standard deviation $=19.840$ ).

\section{Model Testing}

To test the model, the path analysis procedure of the LISREL VIII software program (Jöreskog \& Sörbom, 1993) was used. Due to sample size limitations, the use of single indicators for each variable was preferred to latent variable modelling. The Figure 1 model was tested for the "Principles" and "Gap" web sites, respectively. Results showed that the initial fit of the model (applied to 
both sites) was not satisfactory for either site and some modifications were necessary. In particular, the initial chi square for both "Principles" and "Gap" were significant and more importantly the RMSEA indices of fit were unacceptably high (Principles fit statistics: $\chi^{2}(1)=4.650, p=0.0311$, RMSEA $=0.188$; GFI $=0.986$; and AGFI $=0.704$; Gap fit statistics: $\chi^{2}(1)=8.530, p=0.003$, RMSEA $=0.270 ; \mathrm{GFI}=0.975$ and $\mathrm{AGFI}=0.472$ ). As a result, a model modification procedure was undertaken based on Gerbing and Anderson's (1988) and Kaplan's (1990) recommendations. During the model modification process, care was taken to ensure that the modifications undertaken were based on modification indices that were simultaneously high for both sites on which the model was applied (i.e., Gap and Principles) and that the indicated changes were theoretically meaningful (Gerbing \& Anderson, 1988; Kaplan, 1990). At the end of the process, two models with satisfactory goodness of fit emerged (see Figure 2 and Figure 3). The resulting chi-square $\left(\chi^{2}(4)=5.166\right.$ ) for "Principles" was insignificant ( $\mathrm{p}$-value $=0.271$ ) and all the other indices of fit followed suit (see fitted model and other fit statistics in Figure 2). The fit of same model in the case of the "Gap" web site was also acceptable (see fitted model and fit statistics in Figure 3).

\section{Hypotheses}

\section{Involvement}

Hypotheses $1 \mathrm{~A}$ predicts that consumer involvement with a product category will be positively related to the length of time a consumer spends on the web site related to that product category. Our analysis (Figure 2 and 3) does not support Hypotheses 1A for either "Gap" or "Principles". No difference in the duration of visit was observed between high and low involvement respondents with regard to the "Gap" web site. In contrast, with "Principles" involved consumers were found to spend less time at the web site than less involved consumers. Hypothesis $1 \mathrm{~B}$ predicts a positive relationship between involvement and respondents' attitudes towards a web site. Results failed to support Hypotheses 1B. In the modified models (depicted in Figure 2 and Figure 3), this path had to be removed as involvement was found to have no effect on respondents' attitudes towards either web site $\left(A_{\text {web }}\right)$.

\section{Internet Experience and Knowledge}

Hypothesis 2A postulates that Internet experience is negatively related to the length of time an individual spends at a web site. This hypotheses is partially supported; that is, the relationship holds on the "Principles" web site, but not on the "Gap" web site. As can be seen in Figure 2, experience is significantly and negatively related to the time respondents spend at the "Principles" web site, however, Figure 3 ("Gap" model), does not show a significant relationship between Internet experience and visit duration. 
Figure 2

The Relationship Between Involvement, Attitudes Towards Principles, Internet Knowledge and Experience, Visit Duration and Attitudes Towards Principle's Web Site

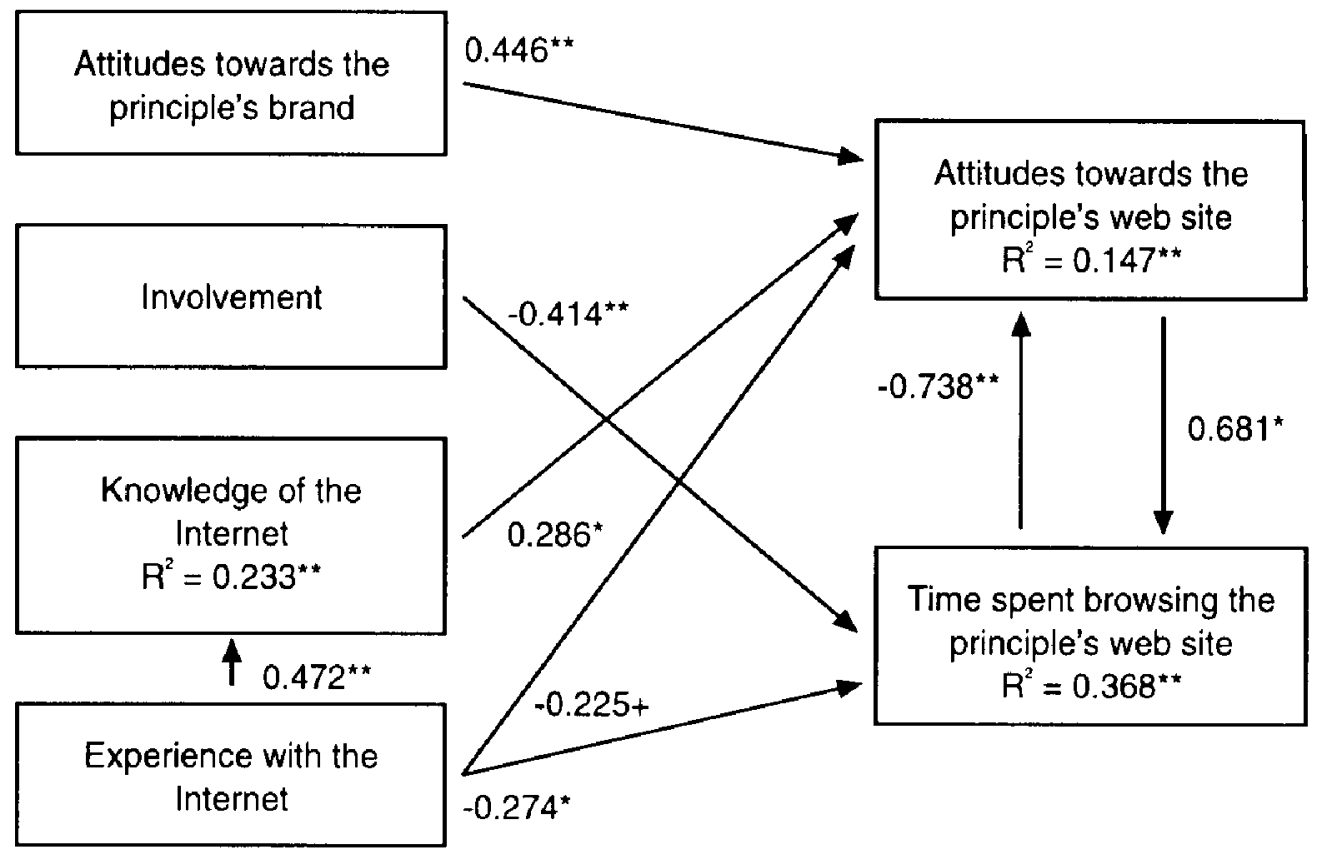

\section{Fit Statistics}

Chi-Square with 4 Degrees of Freedom $=5.166(P=0.271)$; Rool Mean Square Error of Approximation (RMSEA) $=0.0546$; Goodness of Fit Index $(G F I)=0.984$; Adjusted Goodness of Fit Index $(A G F I)=0.914$; Normed Fit Index $(N F I)=0.930$; Comparative Fit Index $(C F I)=0.980$; Incremental Fit Index (IF $)=0.983$

Where: * significant at $\alpha=0.01 ;{ }^{*}$ significant at $\alpha=0.05 ;+$ significant at $\alpha=0.1$

Hypothesis 2C, that Internet knowledge is negatively related to visit duration, is not supported with either web site. This relationship was excluded from the modified model; it was insignificant and detrimental to the model's fit (Figures 2 and 3 ).

Hypothesis 2B assumes that Internet experience will affect the way individuals assess different web sites. This hypothesis is supported in the "Principles" case but only at a confidence interval of $90 \%$ (Figure 2); experienced respondents gave lower ratings to the "Principles" web site than inexperienced ones. However, the same is not true in the "Gap" case (Figure 3) where experience was found to be unrelated to attitudes towards the "Gap" web site. 
Figure 3

The Relationship Between Involvement, Attitudes Towards Gap, Internet Knowledge and Experience, Visit Duration and Attitudes Towards Gap's Web Site

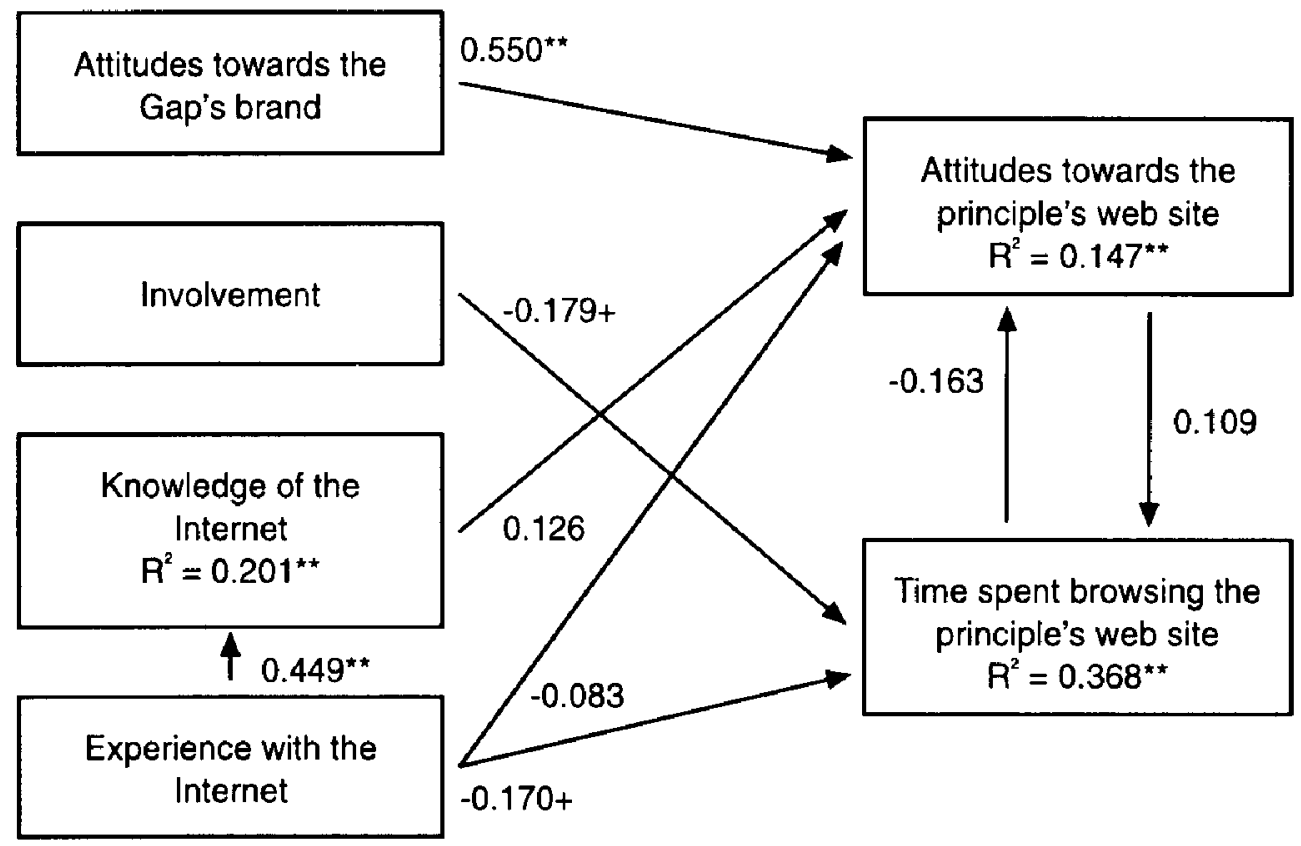

Fit Statistics

Chi-Square with 4 Degrees of Freedom $=9.623(P=0.0473)$; Root Mean Square Error of Approximation (RMSEA) $=0.117$; Goodness of Fit Index $(\mathrm{GFI})=0.972$; Adjusted Goodness of Fit Index $(A G F I)=0.852$; Normed Fit Index $(N F \mid)=0.900$; Comparative Fit Index $(C F I)=0.931$; Incremental Fit Index $(\mathrm{IFI})=0.939$

Where: ** significant at $\alpha=0.01 ; "$ significant at $\alpha=0.05 ;+$ significant at $\alpha=0.1$

Hypothesis 2D postulates that individuals with knowledge of the Internet will evaluate web sites in a different manner to less knowledgeable individuals. Results in Figure 2 seem to support this view as knowledgeable respondents gave higher ratings to the "Principles" web site than less knowledgeable ones. However, the impact of knowledge of the Internet on respondents' attitudes towards the "Gap" web site (Figure 3) was statistically insignificant.

Hypothesis $2 \mathrm{E}$ assumes that Internet experience is positively related to Internet knowledge. It is supported by the data. 


\section{Attitudes Towards the Brand}

Hypothesis $3 \mathrm{~A}$ predicts that individuals with positive attitudes towards a brand will also have positive attitudes towards that brand's web site. Findings in both cases (Figures 2 and 3 ) support this hypothesis. In contrast, Hypotheses 3B (an individual's brand attitude is positively related to the length of time that hel she will spend at that brand's web site) is not supported. The postulated path had to be removed from both the "Gap" and the "Principles" models as it was statistically insignificant and adversely affected the models' fit.

\section{Visit Duration}

Hypothesis 4A claims that individuals will spend more time at web sites towards which they have positive attitudes. The results for the "Principles" model (Figure 2) support this hypothesis, however, no significant relationship is observed on the "Gap" web site. Hypothesis 4B postulates that the time an individual spends at a site will affect his/her attitudes towards the site. Again, Hypotheses 4B is true for the "Principles" web site where a negative effect is observed (Figure 2) but not for the "Gap" web site (Figure 3). Consequently, Hypotheses $4 \mathrm{~B}$ can only be partially supported.

\section{Discussion}

The main finding of this study is that prior attitudes of consumers towards a brand transfer into attitudes towards the web site associated with that brand. Consumers are biased in their assessment of web sites and brand owners need to consider the likely predispositions of consumers when designing, evaluating and implementing their web strategy. As images or attitudes external to the web site transfer to the consumers' assessment of the web site, traditional retailers and other organizations planning to introduce web sites should exploit their existing brand online. The complementary nature of the relationship between on- and off-line branding is encouraging to established brand owners in the face of the recent threats coming from the emergence of intelligent search engines that facilitate the online comparison of price and other product attribute (Mitchell, 2000). While the Internet has seen some strong e-brands surfacing as technology matures, it is nevertheless "consumer behavior that drives the market and redefines your brand" (Thompson, 2000, p. 90). This study confirms the influence of existing brand attitudes on the attitude formation of online shoppers. Harvin (2000) suggest consumers are more comfortable with organizations that have strong off-line brands that they already know and trust. As such, this study provides reassurance to multichannel retailers who compete with an ever increasing number of e-brands (Dignam, 2000); a strong offline brand will help them compete effectively in the online environment (Auton, 2000; Karas, 2000; $\mathrm{McW}$ illiam, 2000). Moreover, as traditional retailers are perceived as loosing ground to manufacturers on the Internet battlefield, strong brand names provide 
an important advantage to the retailers (McElnea, 2000). A complication, however, exists for web sites that carry multiple brands (e.g., e-malls). The success of these web sites is likely to depend on attracting the right combination of complimentary brands to be able to build a successful Internet brand.

Another important finding of this study concerns visit duration (one aspect of the "stickiness" of a web site), a highly regarded attribute that is used for the ranking of different sites (see rankings at Adweek, 4/5/00, p. 45) and as an indicator of web site effectiveness ${ }^{7}$ (Hoffman \& Novak, 1996; Raman \& Leckenby, 1998). Unfortunately our results show that the duration of a visit to an electronic shopping site does not ensure positive attitudes towards that site; longer visits can actually result in less (even un-) favorable attitudes towards the web site in question. Thus, from a practical point of view, visit duration, if used in isolation as a measure of effectiveness may result in an inaccurate reading of a web site's appeal to visitors. Internet retailers must move away from interpreting lengthy visits as an indication of positive attitudes towards the site. Moreover, the observed inconsistency on the impact of visit duration on the two sites researched suggests that a web site's features and content moderate the relationship between visit duration and attitude towards the web site.

Involvement with the product category was also considered in this study. Involvement is known to be an important element of Internet purchasing behavior (Bulter \& Peppard, 1998), however, it is not sufficient, in isolation, to drive a consumer to spend more time at a web site. Indeed, our results suggest highly involved consumers may spend less time on a web site than uninvolved consumers. This may be because the involved consumer is already aware of the alternatives available. Nevertheless, if involvement is not enough to hold the consumer, then in-site motivation (i.e., features/content) may be required. However, the web site manager should not forget that extending the stay of the consumer is only necessary if it has an impact on the objectives of the web site (e.g., do longer visit durations result in increased revenues from the visitor in question).

Finch (1999) showed how important the Internet can be when building consumer involvement for a product category, however, he did not examine how increased involvement affected consumers' online shopping behavior. The findings of this study suggest that individuals with increased involvement may be more demanding of a web site. Web site features and content can either maintain or quickly vaporize the elevated interest of involved visitors (as appeared to happen with the "Principles" site). From a practical point of view online retailers should design web sites that sustain the interest of highly involved consumers; a very influential and sought after category of consumers that tend to be opinion leaders in that category of products (Mowen \& Minor, 1998, p. 494). Nevertheless, despite the evidence that suggests involved consumers are more demanding of web sites, involvement was not found to have a direct effect on consumers' attitudes towards the web sites in this study. 
The final part of this study that needs to be discussed is the relationship between Internet experience and Internet knowledge with both attitudes toward the web site and visit duration. The findings from this study do not give clear-cut answers to these relationships; the characteristics of the web site concerned appear to have an impact on the relationships considered. Internet experience, in the context of the "Principles" web site, did impact upon visit duration. This negative relationship may be explained by inexperienced users being less competent on the Internet and loosing time finding their way through a web site, as such, experienced users spend less time on a site that inexperienced ones. However, as experienced users gave lower ratings to the "Principles" site than less experienced ones, it would appear that the web site did not hold the interest of the more experienced Internet users. In contrast, on the "Gap" web site, which used more visuals and had a greater number of technically advances features, there was no difference in visit duration between experienced and inexperienced users. The design of this web site provided more challenges to experienced users and consequently maintained their interest (Hoffman \& Novak, 1996). Nonetheless, this seems contrary to the findings reported by Hammond, McWilliam and Narholz (1998) who found that, for experienced users, the hedonic aspects of the web site are less important than the utilitarian ones. However, as this study did not attempt to discern the contribution of the different aspects of attitude formation, advice on how to maintain the interest of knowledgeable users is contradictory. However, as Hammond et al.'s (1998) study suggested that users' appreciation of a web site is not linearly related to their experience with the medium and the present study is based on a linear model, this study may not have captured possible non-linearities in the relationship between experience and web site rating.

Turning to the effect of Internet knowledge on visit duration and attitude towards the web site shows no relationship between knowledge and visit duration, however, more knowledgeable respondents are more positive about the "Principles" web site than less knowledgeable ones (no relationship on the "Gap" web site). Knowledgeable respondents are more aware of the technical difficulties and the 'cost' of different web site features in terms of web site functionality (e.g., download time). So, while Internet knowledge is unlikely to have a direct impact on visit duration, knowledge may lead to an appreciation of why novel features are not included on a site, and as such, lead to more positive attitudes towards relatively simply web sites. In addition, the operationalization of Internet knowledge in this study measured theoretical knowledge, but not the navigational ability of the respondent, and this may have had an impact on the results. Nevertheless, the inconsistencies between the effects of Internet knowledge and Internet experience strongly suggest that they need to be treated differently by marketers. It appears that different web site features are appreciated by knowledgeable users and experienced users. Consequently, online retailers aiming to appeal 
to consumers of different levels of Internet knowledge or Internet experience need to adapt their web sites in the appropriate manner.

\section{Conclusions and Topics for Future Research}

This study throws light onto a little researched area, consumers' attitudes towards multi-channel retailers' web sites, and identifies the impact product involvement, brand attitude, Internet knowledge/experience and visit duration on consumer attitudes. Although the study focused on one type of web site, that is, electronic shopping sites owned by multi-channel retailers, the application of the findings may also be extended to the other types of sites (Hoffman and Novak, 1996). The impact of brand attitude on attitude towards websites is, for instance, unlikely to be restricted to retailers. Attitudes towards informational sites, such as www.yell.com, are also likely to be affected by the users' attitude towards their offline brand. In addition, the impact of the differences in behavior based on the users' level of Internet experience, and their level of Internet knowledge, measures sometimes considered interchangeable, are likely to apply to all types of web sites.

Nevertheless, the conclusions that can be drawn from this study alone are limited to the specific research questions explored and, as such, several areas for future research remain. These include those given below.

(i) Different retailers seem to follow different brand transfer strategies (from the physical store brand to the online brand) (Morrison, 2000); future research should examine which elements of the physical brand transfer successfully to the associated web site.

(ii) Future research also needs to consider the extent to which consumer attitudes towards specific brands influences their attitudes towards web sites that are associated with multiple brands. (iii) The observed inconsistency in the relationship between visit duration and attitude towards the web site suggest that factors other than those examined in this study moderate the relationship. Future research should examine this effect on a larger number of sites and should try to isolate the site features that generated these deviations.

(iv) From the results of this study product involvement is not, in itself, sufficient to encourage consumers to spend time on a web site, however, it may be that features and functions on the web site could be used to involve the consumer more with the product category online. Future research could investigate the role of involvement and motivation emanating from the web site on attitude towards the web site as well as visit duration. 
(v) In relation to the previous area for future research, the relationship between product involvement and visit duration needs to be expanded to include more types of sites. It may be that the relationship hinted at in this study was context specific. Future research could, for instance, allow respondents a less restricted choice of web sites, or investigate different types of web sites (e.g., information sites).

(vi) In this study, an overall measure of attitude towards web sites was used, however, the findings using this measure were unclear. Research considering the consumers attitude towards different aspects of the web site (e.g., hedonic/utilitarian value) could provide more insight into the relationships hypothesized in this study.

(vii) Although only tentatively, this study shows that consumers with different levels of Internet experience and different levels of Internet knowledge react differently to the same web site. Future research should isolate the source of these differences as they may provide useful segmentation variables for e-stores.

\section{Notes}

${ }^{1}$ Experience with the Internet refers to the length of time and frequency with which somebody has used the Internet. Knowledge of the Internet refers to an individual's technical understanding of the new medium that can be acquired by other means except experience (studying of manuals, training, etc.).

${ }^{2}$ More specific factors, such as, web-interface knowledge and experience may also have an impact on the duration of users' visits to web sites, and their attitudes towards web sites, however, practical limitations restricted this study to measures of broader Internet knowledge and experience.

${ }^{3}$ The user friendliness of the web site (i.e., logical and consistent screen layout and linkage structure; easily recognizable metaphors; appropriate organization of data, functions, features and tasks; efficient navigation schemes; and high quality appearance characteristics) is also an important factor with regard to web site usage duration and frequency.

${ }^{4}$ Arithmetic mean and standard deviation of the (5-item, 7-point) aggregate scale in appendix 2 (range $=5-35$ )

${ }^{5}$ Arithmetic mean and standard deviation of the (7-item, 7-point) aggregate scale in appendix 3 (range $=6-42$ )

" Stickiness, also considers the visit frequencies of users, and their typical usage patterns.

${ }^{7}$ Effectiveness might, for example, be measured by how quickly a user is able to find information on a web site (informational sites), or the extent to which the web site enhances the brand (branding sites). 


\section{References}

Aaker, D. A. (1996). Measuring brand equity across products and markets. California Management Review 38 (3), 102-120.

Auton, F. (2000). Brands still stay centre stage in the dotcom era. Marketing, Apr 27, 2021.

Berthon, P., Pitt, L. \& Watson, R. (1996). Marketing communication and the World Wide Web. Business Horizons, September-October, 24-32.

Brown, S. P. \& Stayman, D. M. (1992). Antecedents and consequences of attitudes towards the Ad: A meta-analysis. Journal of Consumer Research.19 (June), 34-51.

Butler, P. \& Peppard, J. (1998). Consumer purchasing on the Internet: Processes and prospects, European Management Journal. 16 (5), 600-610.

Celsi, R. \& Olson, J. C. (1988). The role of involvement in attention and comprehension process. Journal of Consumer Research, 15 (2), 210-224.

Chaiken, S., Liberman, A. \& Eagly A. H. (1989). Heuristic and systematic processing within and beyond the persuasion context. In Uleman, J. S. \& Bargh, J. A. (Eds.) Unintended Thought. (212-252). New York: Guilford.

Dholakia, U. M. \& Rego, L. L. (1998). What makes commercial Web pages popular? An empirical investigation of Web page effectiveness. European Journal of Marketing. $\underline{32}(7-8), 724-737$.

Dignam, C. (2000). Old brands face a battle for survival in the dotcom age. Marketing, Mar 16, 17.

Dreze, X. \& Zufryden, F. (1997). Testing web site design and promotional content. Journal of Advertising Research. March/April, 77-91.

Finch, B. J. (1999). Internet discussions as a source for consumer product customer involvement and quality information: An exploratory study. Journal of Operations Management. 17 (5), 535-556.

Gardner, M. P., Mitchell, A. A. \& Russo, J. E. (1985). Low involvement strategies for processing advertisements. Journal of Advertising. 14 (2), 4-13.

Gerbing, D. W. \& Anderson, J. C. (1988). An updated paradigm for scale development incorporating unidimensionality and its assessment. Journal of Marketing Research. 25 (May), 186-192. 
Gupta, S. \& Chatterjee, R. (1997). Consumer and corporate adoption of the worldwide web as a commercial medium. In Peterson, Robert (Ed.) Electronic Marketing and the Consumer. Thousand Oaks, CA: Sage.

Hair, J. F., Anderson, R. E., Tatham, R. L. \& Black W. C. (1995). Multivariate Data Analysis (2nd ed.). New Jersey: Prentice Hall.

Hamill, J. \& Gregory K. (1997). Internet marketing in the Internationalisation of UK SMEs. Journal of Marketing Management, 13, 9-28.

Hammond, K., McWilliam, G. \& Narholz, D. A. (1998). Fun and work on the Web: Difference in attitudes between novices and experienced users. Advances in Consumer Research, 25, 372-378.

Hammond, K., Emmanouilides, C., Turner, P. \& Barwise, P. (1998). Consumer adoption of electronic commerce: Initial results. Proceedings of the 27th EMAC conference, Stockholm, Sweden, 6, 575-583.

Harvin, R. (2000). In Internet branding, the off-lines have it. Brandweek, Jan 24, 41 (4), $30-31$.

Hill R. P. \& Mazis M. B. (1986). Measuring emotional responses to advertising. Advances in Consumer Research, 164-169.

Hofacker, C. F. \& Murphy, J. (1998). World Wide Web banner advertisement copy testing. European Journal of Marketing. 32 (7-8), 703-713.

Hoffman D., Novak T. \& Chatterjee, P. (1995). Commercial scenarios for the Web: Opportunities and challenges. Journal of Computer Mediated Communications, 1 (3), (http//jemc.mscc.huji.ac.il/index)

Hoffman, D. L. \& Novak, T. P. (1996). Marketing in hypermedia computer-mediated environments: conceptual foundations. Journal of Marketing, 60 (3), 50-69.

Johnson, B., Cleland, K., Williamson, D. A., Carmichael, M., Gleason, M., Cuneo, A. Z., Mandese, J., Waltner, C., Donaton, S., Zbar, J. D., Haran, L. \& Fawcett, A. W. (1995). Ad Age's cybermarketing leaders. Advertising Age, Sept 18, 66 (37), 15 (5).

Johnson, B. T. \& Eagly, A. H. (1989). Effects of involvement on persuasion: A metaanalysis. Psychological Bulletin. 106, 290-314.

Johnson, B. T. \& Eagly, A. H. (1990). Involvement and persuasion: Types, traditions, and the evidence. Psychological Bulletin, 107, 375-384.

Jöreskog, K. G. \& Sörbom, D. (1993). LISREL 8: User's reference guide, Scientific Software International 
Kaplan, D. (1990). Evaluating and modifying covariance structure models: A review and recommendations. Multivariate Behavioral Research. 25 (2), 137-155.

Karas, J. (2000). Domain names emerge as key tools for on-line retail marketing. Stores, $\underline{82}(5), 94$.

Katros, V. (2000). A note on intemet technologies and retail industry trends. Technology in Society, 22 (1), 75-81.

Keeling, K. A., Fowler, D. \& McGoldrick, P. J. (1998). Electronic banking customers: Determinants of adoption and retention. Proceedings of the 27 th EMAC conferm ence, Stockholm. Sweden, 6, 535-554.

Keeling, K. A. \& McGoldrick, P. J. (1997). The acceptance of electronic shopping: A question of control? Proceedings of the 26th EMAC Conference, Warwick, UK, 2 , 669-688.

Laaksonen P. (1994). Consumer involvement: Concepts and research. London: Routledge

Leong S. M. (1993). Consumer decision making for common, repeat-purchase products: a dual replication. Journal of Consumer Psychology, 2 (2), 193-208.

Liang, T. \& Huang, J. (1998). An empirical study on consumer acceptance of products in electronic markets: A transaction cost model. Decision Support Systems, 24 (1), 29 43.

Maclnnis, D. J. \& Jaworski, B. J. (1989). Information processing from advertisements: toward an integrative framework. Journal of Marketing, 53 (4), 1-24.

MacKenzie, S. B., Lutz, R. J. \& Belch, G. E. (1986). The role of attitude toward the ad as a mediator of advertising effectiveness : a test of competing explanations. Journal of Marketing Research, 23 (2), 130-144.

Maheswaren, D. \& Meyers-Levy, J. (1990). The influence of message framing and involvement. Journal of Marketing Research, 27 (August), 361-367.

McElnea, I. K. (2000). Who will own the consumer of the 21 st century? Brandweek, Mar $13,41(11), 32-37$.

McMurdo, G. (1998). Evaluating Web information and design. Journal of Information Science, 24 (3), 192-205.

McWilliam, G. (2000). Building stronger brand through online communities. Sloan Management Review, 41 (3), 43-54.

Mitchell, A. (2000). Web presents acid test for brand robustness. Marketing Week. Mar $2,23(4), 44$. 
Morrison, G. (2000). Getting the Web site to click with the brand within the bricks. Brandweek. Apr 10.41 (15), 50-52.

Mowen, C. J. \& Minor, M. (1998). Consumer behaviour. New York: Prentice Hall.

Nunnally, J.C \& Bernstein, I. H. (1994). Psychometric theory. New York: McGraw Hill Inc.

O' Keefe R. M., O'Connor, G. \& Kung, H. (1998). Early adopters of the web as a retail medium: small company winners and losers. European Journal of Marketing. 32 (78), 629-644.

Olney, T. J., Holbrook, M. B. \& Batra, R. (1991). Consumer responses to advertising: The effects of ad content, emotions, and attitude toward the ad on viewing time. Journal of Consumer Research. 17, 440-453.

Park, C. W., Mothersbaugh, D. L. \& Feick L. (1994). Consumer knowledge assessment. Journal of Consumer Research 21 (1), 71-82.

Petty, R. E (1994). Two routes to persuasion; State of the art. In d'Ydewalle, G., Eelen, P., \& Bertelson, P. (Eds.) International Perspectives on Psychological Science, 2, (229-247). Hillsdale, NJ: Erlbaum

Petty, R. E. \& Cacioppo J. T. (1986). The elaboration likelihood model of persuasion. In Berkowitz, L. (Ed.) Advances in Experimental Social Psychology. (123-205). Orlando: Academic Press.

Quelch J. \& Klein L. (1996). The Internet and international marketing. Sloan Management Review, Spring, 60-75.

Raman, N. V. \& Leckenby, J. D. (1998). Factors affecting consumers' "Webad" visits. European Journal of Marketing, 32 (7-8), 737-749.

Settles, C. (1995). Cybermarketing:Essentials for success. New York: Ziff-Davis Press.

Thompson, D. (2000). Branding hasn't changed much. MC Technology Marketing Intelligence. 20 (4), 90-95.

Thorson, E., Chi, A. \& Leavitt, C. (1992). Attention, memory, attitude, and conation: A test of the advertising hierarchy. Advances in Consumer Research, 19, 366-379.

Vrolijk, H., Huizingh, C. J., Eelko, K. R. E.; \& Hoekstra, J. C. (1998). Experimental research on the effectiveness of Web sites. Proceedings of the 27th EMAC conference, Stockholm. Sweden. 4, 299-311. 
White, M. D., Abels, E. G. \& Murnane, L. (1998). What constitutes adoption of the Web: A methodological problem in assessing adoption of the World Wide Web for electronic commerce. Proceedings of the ASIS Annual Meeting. 35, 217-226.

Zaichkowsky, J. L. (1985). Measuring the involvement construct. Journal of Consumer Research. 12 (December), 341-352.

\section{Appendix 1 \\ Involvement with Casual Clothes}

\begin{tabular}{lc}
\hline \multicolumn{1}{c}{ Items } & $\begin{array}{c}\text { Standardized factor } \\
\text { loadings }(\lambda)\end{array}$ \\
\hline important/unimportant (r) & 0.801 \\
of no concern to me/of concern to me & 0.731 \\
means a lot to me/ means nothing to me (r) & 0.863 \\
valuable/worthless (r) & 0.733 \\
trivial/fundamental & 0.719 \\
beneficial/not beneficial (r) & 0.622 \\
matters to me/ does not matter to me (r) & 0.874 \\
uninterested/interested & 0.696 \\
essential/nonessential (r) & 0.789 \\
undesirable/desirable & 0.800 \\
wanted/unwanted (r) & 0.733 \\
& \\
(r) $=$ reversed item & \\
Reliability/validity statistics & \\
Construct validity & \\
Extracted variance & 0.938 \\
Cronbach's alpha & 0.641 \\
& 0.938 \\
Fit statistics & \\
$\chi^{2}(44)$ & \\
p-value & 53.411 \\
Root Mean Square Error of Approximation (RMSEA) & 0.156 \\
Goodness Of Fit Index (GFI) & 0.051 \\
Adjusted Goodness Of Fit Index (AGFI) & 0.898 \\
Normed Fit Index (NFI) & 0.848 \\
Comparative Fit Index (CFI) & 0.914 \\
Incremental Fit Index (IFI) & 0.983 \\
\hline
\end{tabular}


Appendix 2

Attitudes Towards Retailer's Brand

\begin{tabular}{lcc} 
& Principles & Gap \\
\hline \multicolumn{1}{c}{ Items } & $\begin{array}{c}\text { Standardized factor } \\
\text { loadings }(\lambda)\end{array}$ & $\begin{array}{c}\text { Standardized factor } \\
\text { loadings }(\lambda)\end{array}$ \\
\hline $\begin{array}{l}\text { Good value for money } \\
\text { Innovative }\end{array}$ & 0.620 & 0.619 \\
Admirable & 0.720 & 0.890 \\
High quality & 0.866 & 0.844 \\
Interesting & 0.607 & 0.522 \\
& 0.791 & 0.872 \\
Reliability/validity statistics & & \\
Construct validity & & 0.871 \\
Extracted variance & 0.846 & 0.594 \\
Cronbach's alpha & 0.530 & 0.863 \\
Fit statistics & 0.853 & \\
$\chi^{2}(5)$ & & 2.676 \\
p-value & & 0.750 \\
Root Mean Square Error of & 7.409 & \\
Approximation (RMSEA) & 0.192 & 0.001 \\
Goodness of Fit Index (GFI) & & 0.988 \\
Adjusted Goodness of Fit Index (AGFI) & 0.074 & 0.954 \\
Normed Fit Index (NFI) & 0.971 & 0.967 \\
Comparative Fit Index (CFI) & 0.958 & 0.997 \\
Incremental Fit Index (IFI) & 0.986 & 0.998 \\
\hline
\end{tabular}




\section{Appendix 3}

\section{Attitudes towards Retailer's Web Site}

\begin{tabular}{lcc} 
& Principles & Gap \\
\hline \multicolumn{1}{c}{ Items } & $\begin{array}{c}\text { Standardized factor } \\
\text { loadings }(\lambda)\end{array}$ & $\begin{array}{c}\text { Standardized factor } \\
\text { loadings }(\lambda)\end{array}$ \\
\hline Uninteresting/Interesting & 0.730 & 0.694 \\
Unfavorable/Favorable & 0.822 & 0.880 \\
Poor quality/Good quality & 0.586 & 0.726 \\
Disagreeable/Agreeable & 0.570 & 0.682 \\
Confusing/Clear & 0.747 & 0.560 \\
Low/High attention grabbing ability & 0.781 & 0.644 \\
& & \\
Reliability/validity statistics & & 0.853 \\
Construct validity & 0.858 & 0.496 \\
Extracted variance & 0.517 & 0.838 \\
Cronbach's alpha & 0.851 & \\
& & 13.840 \\
Fit statistics & & 0.128 \\
$\chi^{2}$ (9) & 12.764 & \\
p-value & 0.174 & 0.071 \\
Root Mean Square Error of & & 0.956 \\
Approximation (RMSEA) & 0.069 & 0.898 \\
Goodness Of Fit Index (GFI) & 0.956 & 0.934 \\
Adjusted Goodness Of Fit Index (AGFI) & 0.897 & 0.975 \\
Normed Fit. Index (NFI) & 0.941 & 0.976 \\
Comparative Fit Index (CFI) & 0.981 & \\
Incremental Fit Index (IFI) & 0.982 & \\
\hline
\end{tabular}




\section{Appendix 4 \\ Multiple-choice Test Used to Assess \\ Respondent's Knowledge of the Internet}

i) Yahoo is:

kid's web page.

web searching engine.

An Internet communication service

A tele-shopping organization in the network.

A web browser.

ii) A URL is:

A programming language in the Internet.

Another word for Internet site address.

A web searching engine.

A web browser.

A body regulating internet traffic.

iii) A cookie is:

Another word for net-surfing.

[.. Is a small piece of information that a web server sends to your browseto collect information about you.

.] A computer virus.

$[$ [.] A net-nerd or a net-junkie.

A web security protocol.

iv) Hypertext is:

The connection that brings various bits together to make the web pages.

A spell checker.

A word-processor.

A programming language to design web pages.

A special font.

v) JAVA is:

A web browser.

A computer language.

An Internet service provider.

A chat services in the Internet.

A computer virus. 
George Balabanis is a Senior Lecturer in Marketing at City University Business School. George obtained a B.A. (Hons) in business administration from the University of Pireaus and a Ph.D. in international marketing from the University of Strathclyde. His current projects include country of origin effects on consumer evaluations, Internet marketing and relationship marketing. His research has appeared in the Journal of International Business Studies, European Journal of Marketing, Journal of Global Marketing, and Journal of Marketing Management.

Nina Reynolds is a lecturer in Marketing at the European Business Management School. She obtained a B.Sc. (Hons) in American management studies from the University of Wales and then completed a Ph.D. in international marketing research. Her current projects are in the areas of international marketing research methodology, the sales negotiation process, and Internet marketing. Her work has appeared in the Journal of the Market Research Society, European Journal of Marketing, Journal of Marketing, and Benchmarking: An International Journal. 
